\title{
Language maintenance in friendships: second-generation German, Greek, and Vietnamese migrants ${ }^{1}$
}

\author{
JO WINTER and ANNE PAUWELS
}

\section{Abstract}

Our contribution explores the language maintenance (LM) patterns of children of migrants (second-generation) to Australia from three ethnolinguistic groups - German, Greek, and Vietnamese - in their same-age peer friendships. Focusing on the affective social relationship of "friendship" imagined as a dynamic fluid site of independence and a locale for identity formation, we scrutinize it as a pressure point for LM. The macro survey trends indicate that languages other than English (LOTE) are used in the friendship domain but with differing participations. Follow-up in-depth interviews reveal subtleties and complexities for LM practices. Co-presence of bilingual others in friendships proves to be a minimum but not sufficient condition for LM, particularly for German men and Greek women. Hyphenated belongings — for example, Vietnamese-, Greek-, German-Australians - construct varying LM alignments that reflect shared histories and authenticities (the migration experience) and the localizing of settlement (Australia).

\section{Friendship, identities, and communication}

Commentary about social organization in contemporary (post)modernity has highlighted the transformations to personal relationships and suggested that friendship is of increasing significance (e.g. Giddens 1992). Friendship-based relationships are replacing many traditional forms of family relations or partnering, and increasingly form the basis of transnational movement of peoples. As such, they may "represent the relational genre of the future" (O'Connor 1992: 8). In much LM and language shift (LS) research family relationships and/or domains have been privileged as locales of influence and transmission for ethnolinguistic identities and practices. Familial roles and relationships have been imbued with 
significant social capital in the transmission processes. Focusing on friend(ship)s raises complexities for language choice and maintenance research. It requires consideration of diverse settings, belongings, and identities. It is difficult to reduce friend(ship)s to an uncontested domain of sameness. Recognizing the complexities is a mere beginning, and our goal is to interrogate the discursive practices surrounding LM and friend(ship)s in an attempt to assess the outcomes if Giddens' statements and O'Connor's visions are fully realized. Specifically, our aims in this article are:

1. to document the trends from survey data about reported language use with friends;

2. to explore the LM practices in friendship contexts; and

3. to identify the features of "doing" friendship that impact on LM and LS among second-generation migrants from German, Greek, and Vietnamese backgrounds residing in Melbourne, Australia.

In most survey-based LM research data, the realities of friends(hip) and the spaces taken up for bilingual or LOTE choices are largely underresearched, in part because of the complexity of permutations for friendship. For example, friendship domains more than family domains involve consideration of ethnolinguistic diversity (see Woolard [1997] and Pujolar [1996] for localized ethnographic examinations of language choice and friendships). Further, perceptions about the instability of this "domain" and the possibilities of variable influences on the participants under scrutiny raise a messiness that is methodologically difficult to resolve. Friendship status and roles change at varying rates and times for most people. Friends can be lost through movement or ideological differences, and the ways in which friends communicate and maintain their friendship may change over time as they move from school/study contexts to work. Friends may become closer, with changes to intimacy for shorter or longer periods of time. Friends may become family and establish new homes or belongings. Home and birth family may become more or less close or distant as people's lives and identities mature and change. The transformations are many and to attempt to characterize them all is a task beyond the scope of this article.

Friendship and language research has highlighted gendered practices and gender differences in monolingual and bilingual settings. Much of the research has focused on stylistic differences and linked these to the dominance of same-sex peer friendship (e.g. Maltz and Borker 1982; Goodwin 1990). For example, Coates (1996) argues for the centrality of talk and communication to the maintenance and "doing" of friendship social relations for women. She maintains that the accomplishment of 
discursive strategies is sensitive to friendship and age and that time spent on doing friendship offers women the opportunities to acquire, rehearse, and learn interaction patterns and devices. Kiesling's (1996) examination of an all-male fraternity group exposes the variety of resources that may be exercised in the construction of power and competitive hierarchical relationships. Woolard (1997) establishes that ethnolinguistic diversity, cohesion, and closeness of affective relationships in peer friendships impacts upon the bilingual repertoires in a group of Barcelona high school students. In particular Woolard (1997) showed that girls' friendships were more solidary, with stronger constraints on their linguistic behavior than the more diverse boys' friendship groups and linguistic practices. Friendships can be norm-enforcing as well as norm-challenging.

In considering friend(ship)s as sites for LM we highlight the diversity among and between the ethnolinguistic groups and the many ways in which participation in friendships impact upon bilingualism and LM. Different spaces are constructed as sites of doing friendship and these constructions participate in the transnational reproduction of home, belonging, and LM.

Our research draws upon interviews with second-generation migrants from three ethnolinguistic groups - German, Greek, and Vietnamese resident in Melbourne, Australia. Our theoretical framing draws upon Bakhtin's (1981) notions that the discursive and heteroglossic nature of society is constructed through individuals' articulation of social "voices." These voices are grounded in social and temporal practices and spaces. They give rise to discursive struggles in which we contest the possibilities of change and meaning as we speak with "others" and "selves." This approach to the participants' discursive practices illuminates the performance of bilingual identities and voices within social worlds of friendships. In addition, we argue that the discursive voices articulated by the second-generation bilingual women and men demonstrate their positioning or alignments (Goffman 1981) toward LM and LOTE use in the Australian immigrant context.

\section{Friendship and language maintenance (LM) in the Australian context}

In Australian immigrant language research the family has typically been the locus for the examination of LM patterns, stability, and change, while the examination of friend(ship)s has been more peripheral. One major reason is the focus on macrostudies drawing upon census data which provides statistics typically limited to birthplace, home language use, and, more recently, ancestry. The reference to home language use as a measure 
of linguistic diversity has drawn criticism based on the argument that some people who no longer reside in their family home may actually use a LOTE outside their home residence in interactions with relatives and family (Clyne 1991; Clyne and Kipp, this issue). This type of criticism still privileges home and birth family as the normative sites for LOTE use, as it draws upon discourses which locate constructions of belonging and bilingualism in the family. Of interest for studies of children/descendents of migrants, or the so-called second generation, are the ways in which spaces beyond the birth family and "home" facilitate LM practices and the performing of bilingual identities.

Clyne (1991) suggests that the friendship domain aids LM in the first generation whereas in the second generation, even if same-ethnolinguistic partners marry, they continue their peer age group practice of speaking in English (114). Further Australian research has investigated language use in cross-generation friendships, typically second-generation members speaking with their parents' friends. For example, Bettoni (1981) found that some North Queensland Italo-Australians tend to use a variety of Italian with their parents' friends, while Harvey (1974) indicated that $84 \%$ of second-generation Dutch-Australians would "never" use Dutch to their parents' friends. Smolicz and Harris (1976) found that only 39\% of Polish-Australians, 35\% of Italian-Australians, and 24\% of DutchAustralians would speak the LOTE to their parents' friends.

Tsokalidou's (1994) study of educated second-generation GreekAustralians included aspects of peer friendship and found that all participants had Greek-Australian friends, with all-female groups having a higher density than the male ones. She identified that the primary uses of Greek among friends were for Greek-related topics and as a secret code (Tsokalidou 1994: 222). In terms of same-age friendship research in Australia, Clyne (1991) suggests that in some groups friendship networks may be more organized along ethnic lines than in others and this impacts upon LM. Taking up Clyne's challenge, we explore the composition and participation of the three ethnolinguistic groups in this article.

\section{The study}

The questionnaire findings and interview discourse extracts presented in this article come from a research project (supported by an Australian Research Council Large Grant) on the role of women and men in LM in three ethnolinguistic communities in Melbourne (German, Greek, and Vietnamese). The project surveyed first- and second-generation female and male participants from the communities in question. Questionnaire 
Table 1. Second-generation questionnaire respondents

\begin{tabular}{lllllll}
\hline Language background & \multicolumn{3}{c}{ Sex } & & \multicolumn{2}{c}{ Age (years) } \\
\cline { 2 - 3 } & Female & Male & Total & & Mean & Median \\
\hline German & 10 & 9 & 19 & & 39.42 & 40 \\
Greek & 11 & 8 & 19 & & 25.95 & 27 \\
Vietnamese & 12 & 8 & 20 & & 19.3 & 20 \\
Total & 33 & 25 & 58 & & \\
\hline
\end{tabular}

data were gathered on their language use patterns, their proficiencies in their LOTE and English, and their views on LM and bilingualism. These topics were further pursued in interviews. The data presented here are taken from questionnaires with 58 second-generation German, Greek, and Vietnamese participants (see Table 1), and from in-depth interviews held with thirteen female and thirteen male second-generation bilinguals.

That the median and mean ages differ substantially between the Greek, Vietnamese, and German groups mirrors the migrant histories of these groups in Australia, with the arrival of German migrants first followed by the Greeks and more recently the Vietnamese (see Clyne and Kipp, this issue).

\section{LOTE use in friendship domains}

This section of our article reports the participants' use of LOTE to sameage peer friends.

Remarkable in the findings is the high use of German by women in the friendship domain and the substantial gender difference in this domain. Almost all women report use of German to their friends (90\%), whereas only a third of men $(33.3 \%)$ do so. This is despite the fact that the men's socio-educational profile is similar to that of the women. Table 2 reveals

Table 2. LOTE use with friends

\begin{tabular}{llcc}
\hline Sex & Language background & Speak LOTE with friends & \% of group \\
\hline Female & German & $9 / 10$ & 90.0 \\
& Greek & $7 / 11$ & 63.6 \\
& Vietnamese & $10 / 12$ & 83.3 \\
Male & German & $3 / 9$ & 33.3 \\
& Greek & $6 / 8$ & 75.0 \\
& Vietnamese & $6 / 8$ & 75.0 \\
\hline
\end{tabular}


that the use of Greek still features prominently in the friendship domain for this group of second-generation Greek participants. In contrast to the German group, it is the Greek men who report greater use of Greek to their friends than the women, although the difference is not as marked as it is for the German group. However, the proportion of women using Greek in their friendship domains is lower than that of the German and Vietnamese women. The use of Vietnamese with their friends is substantial among both women $(83.3 \%)$ and men $(75 \%)$. This finding for Vietnamese women mirrors the German women's use of German with friends and the Vietnamese men report similar use patterns to those of the Greek men. As stated earlier, the Vietnamese participants were substantially younger than either the German or Greek participants, with a mean age of just 19.3 years.

These findings diverge somewhat from observations in other Australian LM research (e.g. Bennett 1990; Clyne 1991). For example, while the LOTE use in friendship contexts is not the only language used, it nevertheless features quite frequently and prominently. German men appear to be the exceptions and they conform to an "English only" context for peer interaction. While this finding does not challenge that adolescents and young adults are the age group most likely to use English in domains outside the family and home, it does reveal that LM alignment extends beyond the family/home domain. These intriguing results will be scrutinized for discourses about the composition of friendship networks and the co-presence of bilingual others in such networks.

\section{Friendships - co-presence and language maintenance alignment}

Here we examine the phenomenon of co-presence of bilingual friends from the same ethnolinguistic group in friendships and the consequences for alignment to LM positions. Co-presence of bilingual others in friendships facilitates a possible minimum starting point for a LM alignment. We explore the dynamics of co-presence and the extent to and the ways in which LM voices are invoked for friendship. The analysis focuses on the discursive construction of doing friendship and the co-presence of bilingual others in friendship networks (Milroy 1980).

We include a cautionary note about the role of interviews in the reporting of language practices. Piller (2001) suggests that research interviews are in fact limited by their research context. We acknowledge that what the second-generation speakers say they do may in fact differ from what they actually do in practice. Nevertheless, consideration of the discursive construction of LM enables a focus on the social meanings involved in 
the construction of what people say they do and any implications for LM strategies and language policy.

In the interviews, the German women revealed an alignment of seeking opportunities to use German among existing friendships and in other nonfamily contexts, as demonstrated by these brief extracts:

(1) Ingrid ${ }^{2}$ : also I grasp the opportunities if I can and love to speak to speak German

(2) Sabine: I find I am speaking German more to other people than to than to my family and my parents these days

Marlis confirms this trend - "women seem to seek out German speakers and continue on the German" - generalizing it as a gendered practice undertaken by German women as part of aligning to LM. The intentional pursuit of German-speaking friends, that is, increasing the density of German ethnolinguistic friendship networks and thus enabling co-presence, contrasts with the "apparent" haphazard friendship arrangements experienced by Heike:

(3) Heike: It's weird ... um I mean we've got German friends as well but um they all just speak German I really didn't look out

Whether haphazard, opportunistic, or planned, arrangements with German-speaking friends are clearly central to these women in order to promote an LM alignment. Further, the exigencies due to decreasing LM in the family context has encouraged some German women to actively seek non-home co-presence of German-speaking friends (see the excerpt in [2]). In contrast, the German men who also report co-presence of German-speaking bilingual friends resist or avoid speaking German with their friends. For example, when asked if he spoke German with his peer group, Max talks about explicit strategies not to use German in friendship contexts.

(4) Max: I do make a bit of a conscious effort in the sheer fact that I don't have enough confidence and speak it so I suppose it would be and also I'd be very conscious of them judging the way I would be speaking German so therefore I don't do it

In fact, he argues that he would avoid using German and speak English instead, particularly with friends who he knows have better German than he has - "I have a friend who speaks it fluently." All of the interviews with the German men demonstrated that alleged skill deficit and limited speaking competencies in German combine with discourses of masculinity about fluency and avoidance of the use of German. For example, when 
asked if he spoke German with his peer group, Heinz states, "I would not speak to them in German" (German/English bilingual male same-age peers) and Jurgen likewise says "No" in response to the same question. Another German male participant, Werner, incorporates reference to skills and competency in German and the influence of peers in his observations of his German co-present friends.

(5) Werner: I find that ah the male tends to in their youth they tend to be more how can I say cliquey more ah impressed by I suppose peer group pressure and things like that and they tend to lose their language a lot quicker than women

The German men demonstrate a non-alignment to LM in friendship. Co-presence opportunities are sensitive to discourses of masculinities and power (Kiesling 1996; Pujolar 1996) which require ongoing monitoring to ensure apposite performances. In this case, power is located in linguistic competencies and skills, and in order for the German men to avoid loss of power and reduce risks to their masculinities, a "muted" German voice emerges. We have identified this as a discourse of "masculinities of muting" (Winter and Pauwels 2005). These discourses show that accounting for the non-use or decreasing use of German as simply a lack of competency overlooks the crucial elements associated with the masculinities of orality and performance for these German men. They report privileging English over German, particularly with skilled German-speaking friends. The masculinities of oral performance in peer interaction mean compulsory shifts to English-speaking positions and an absence of LM alignments. The relevance of the co-presence of German-speaking friends plays out differently for the German women and men. The mere inclusion in friendship networks is overridden by affective constraints for the German men due to their reluctance to lose interactional power, and they are forced to "mute" their bilingualism. On the other hand, the co-presence in the German women's experiences are central to supporting their own LM alignments.

All Greek participants indicate that they have quite dense networks of bilingual same-age peer friendships, confirming Tsokalidou's (1994) findings for the Greek second generation. The Greek men report engaging in opportunities to use their Greek in friendship networks in much the same way as the German women.

(6) Michael: ... when I get a chance to speak to friends I'll speak it

(7) Con: you both know the language and if Greek's a better ways to say what you're saying even if it just a about a joke or a swear word or whatever 
For the Greek men, however, the friendship contexts are not grounded as opportunities to compensate for loss elsewhere: their home/family use of Greek is strong and fundamental to their identities. We explore this further in the next section on hyphenated belongings. Interestingly, English seems to prevail in friendship among second-generation Greek women as evidenced by excerpts (8) and (9).

(8) Tina: mainly well mo most of my friends tend to be Greek or second-generation Greeks.... ah with your girlfriend you sort of speak English

(9) Roula: I've always spoken to my friends my Greek friends in English

Co-presence of bilingual others constructs a paradox for the Greek women. On the one hand, co-presence is a robust feature of their friendship systems but it fails to facilitate strong LM alignments. Co-presence of a Greek-Australian girlfriend exerts pressure on members of the dyad to shift to English. While co-presence is influential for closeness and security for these young Greek women the discourse of doing these friendships is constructed through English. This resonates with Woolard's (1997) observations about the smaller, more intimate nature of friendship groups for girls and the consequential conforming influences and constraints placed on their social voices. Co-presence is a prominent feature in the construction of friendship here but it constrains LM alignments. Possible explanations and interpretations of the non-alignments to LM are probed in the next section on hyphenated belongings.

Unlike the Greek women, the Vietnamese women suggest that copresence is an influential factor in LM alignments, as illustrated in excerpts (10) and (11).

(10) Kim: friends at college that are Vietnamese then I speak to them in Vietnamese

(11) Hai: I know they're Vietnamese and they know that I'm Vietnamese then I speak Vietnamese to them

It appears that Vietnamese women not only have extremely strong LM alignments in the home/family but also beyond. They adopt strong LM alignments with their friends even in the school/university context. Copresence in these settings results in LM alignments. At the same time, the women indicate that they are competent bilinguals in both English and Vietnamese but personal emotions are the reasons behind their use of Vietnamese, as illustrated in excerpt (12). 
(12) Bien: I speak both English and Vietnamese, I feel it is dearer to speak Vietnamese

All interviewees, male and female, report use of mainly Vietnamese to female siblings and friends and increased use of English to male friends or in all-male contexts.

The complexities of co-presence and migration vintages emerge from the interviews with young Vietnamese men, who indicate that they are in contact with many friends who are recent arrivals to Melbourne. For example, Bao says, "coz I know a lot more variety of friends" (Vietnamese friends). Co-presence of Vietnamese friends is pivotal to their networks but it includes both same-age first-generation and same-age second-generation bilingual migrant friends. English and Vietnamese is used with their friends and for some, interactions may be conducted entirely in Vietnamese. Language choice is partly based on linguistic competency and fluency and hyphenated belongings (see below). Like the German men, they experience difficulties at times speaking Vietnamese (13) and (14) and shift to English, but unlike the German men, interacting with competent Vietnamese-speaking others facilitates their own LM practices.

(13) Lam: because it's hard to um articulate, how I u ... my ideas, um and my opinions in Vietnamese sometimes

(14) Bao: if their expression like their Vietnamese is more clear then I will also use Vietnamese ... good to backstab and that

The Vietnamese second-generation men echo aspects of the competency voices articulated by the German men. For example, Lam highlights the importance of being able to perform a skilled, articulate voice with samesex peers. Performances of masculine linguistic power associated with knowledge and rhetoric motivate the choice of English for these men in those friendship contexts with bilingual second-generation friends. However, like the Greek men, they are domiciled in family homes with strong LM practices and attitudes. Unlike their older Greek colleagues, English is the language that is preferred and holds most status in friendship organization, with use of Vietnamese if initiated by co-present others who are competent speakers of Vietnamese. It appears that co-presence exerts pressure on speakers to maintain linguistic power and simultaneously ensures deference to others through adopting a LM alignment to them through the use of Vietnamese.

Based on these findings we note that co-presence of bilingual others is an essential ingredient for LM alignment in friendship but that it is 
not sufficient to promote LM, as evidenced by the practices of secondgeneration German men and Greek women. Further, we found evidence that LM alignment in friendships intersects with gendered practices and ethnolinguistic migration histories and realities (Clyne and Kipp, this volume). The next section explores the construction of hyphenated belongings and LM alignments in the doing of friendship among secondgeneration migrants.

\subsection{Hyphenated belongings and friends}

Previous research (Winter and Pauwels 2000, 2005) has identified constructions of masculinities and femininities as central to LM alignments. Intertwined are hyphenated belongings or "cultural hybridity" (Kalantzis 1993) as resonances of LM alignments. Hyphenated belongings Vietnamese-, Greek-, German-Australian - capture the sociohistorical present of their bilingual identities as second-generation migrants and first-generation locals. Hyphenated belongings reflect the shared histories, families, and backgrounds - German, Greek, Vietnamese - and the locale of friendship: Australia. Synergies and tensions of hyphenated belongings recur in the second-generation discourse. In this section, we investigate the ways in which hyphenated belongings impact upon LM alignments in friendship co-presences. The analysis of hyphenated belongings explores the relevance of language choice and LM in the doing of friendship. It attempts to identify the responses to shared histories (largely family and home supported) in localized (multicultural Australia) friendship settings. We discuss, if relevant, how the participants draw upon and voice their hyphenated belongings in establishing LM alignments.

For many of the second-generation participants, their hyphenated belongings emerge through their use of LOTE in friendships. These emerging belongings vary across gendered and ethnolinguistic groups as well as in terms of degrees of LOTE use. These may include minimal LOTE use - single words or expressions - to bring about the shared histories as voiced by Vasilis in excerpt (15).

(15) Vasilis: ... if you speak English to someone who speaks Greek you know they're going to listen to you so ev even if you go and say now listen here thio ${ }^{3}$ you know I he he'll shut up and pay attention

Vasilis suggests that authority and respect are located within Greek LM alignments, even if the only Greek used is an exhortative honorific thio. 
Such discourses (see Winter and Pauwels [2005] for elaboration of masculinities of authenticity) resonate with cultural traditions as well as the perspectives of Greek masculinities, power, and prestige associated with the Greek voice in their hyphenated belonging. Michael (16) echoes this authenticity for hyphenated belongings as part of Greek male LM alignments.

(16) Michael: if the other person has this very Greek attitude and he's speaking Greek to me then I won't hesitate to speak Greek back to them

For Michael, hyphenated belongings are not simply linked to matched co-presence, but associated with performances of Greek attitude. According to him, shared histories of their hyphenated belongings require understanding of what it means to construct Greek attitude in friendships and LM alignments. For second-generation Greek men, shared histories and performances of authentic Greek masculinities are central to their LM practices in resolving hyphenated belongings. For these men, use of Greek is not problematic or problematized due to compulsory LM alignments: it demands to be used in response to Greek attitude and to ensure respect.

Perhaps the most perplexing issue of hyphenated belonging resides in the Greek women's preference of English in their friendship dyads. As noted earlier, co-presence is an integral component for these women. They operate in strong family contexts of Greek, speak Greek to their babies and young children (Winter and Pauwels 2000, 2005), promote LM for future and present generations, but resist Greek in intimate friendships with other young second-generation Greek women. Linking this problematic to Callan and Gallois' (1982) findings that showed strong positive language attitudes toward Australian English and the concomitant social identities for Greek women proves helpful. It would appear that for these young Greek women, the doing of friendship in close-knit dyads requires the shift to English because it provides hyphenated belongings linked to the Australian setting. The doing of friendship reflects the Australian setting of their hyphenated belongings. English aspects of their hyphenated belongings and identities are constructed as prestigious and possibly liberating (Winter and Pauwels 2000). Friendship for these Greek women is seen as separate from shared families while also featuring shared understanding of histories and hyphenated belonging. These findings also echo Gal's (1978) work on gendered bilingualism practices and femininities. Meanings of social and individual affective relations resonate with ideas of sophistication, and integration. 
It should be remembered that our survey data still showed more than $60 \%$ using some Greek to their friends and we could also speculate that Greek women under-report their use of Greek in friendships. In the interviews, however, the young Greek women identified English as the language of co-present friendships. We have not included aspects of the participant observation ethnographies that are part of the larger project, which document substantial Greek code-switching in the friendship domain, echoing Tsokalidou's (1994) results. Nevertheless, even the under-reporting strengthens the case of English language practices as constructing hyphenated belongings in friendship for these young women. Resolution of tensions and individual identities for their hyphenated belongings has resulted in LM being reserved largely for in-group family/ home contexts. For these women, hyphenated belongings seem to emphasize the settlement locale and the use of English rather than LM alignments through the shared histories and co-presence of their friendships.

Hyphenated belongings and authenticity for the second-generation Vietnamese-Australians overtly expose the underlying transnational processes of migration and settlement. It seems that the elements on either side of the hyphen are constructed as distinct and different. For example, Trinh's discourse (17) constructs a separation of Vietnamese and Australian in her observations about boys and their preference for English in friendship networks.

(17) Trinh: most of the boys here usually want to adopt Australian lifestyle they don't want to retain Vietnamese lifestyle

LM alignments and hyphenated belongings for the VietnameseAustralian women preference shared histories and lifestyles even in their friendship practices. Unlike the Greek women, their participation in friendship settings is not constructed around new settlement experiences or prestige associated with English. Like the Greek women, they express strong familial connections to language and desires for LM for future generations, but these wishes and support mechanisms have been transferred to co-present friendships. In the case of Vietnamese men, their hyphenated belongings intertwine with compulsory LM alignments if shared histories are evoked through good language skills, although they will shift to English in other friendship contexts in order to secure masculine linguistic power. Their hyphenated belongings apply consideration of Vietnamese migration, based on linguistic competencies and Australian settlement to ensure linguistic prestige. Further, the Vietnamese men show obligations to their hyphenated belongings and LM alignments in consideration of other co-present language skills, and not just because of attitudes and authenticities constructed for Greek men. 
The issue of hyphenated belongings as part of the non-LM alignment for the second-generation German men shows a suppression of or reduced relevance for shared histories. Conflicts or tensions with hyphenated belongings do not emerge in the friendship discourses. It would seem that co-presence and competency issues assume precedence in their nonLM alignments.

Hyphenated belongings prove to be powerful components in the taking up of LM alignments in the co-presence of bilingual friends. For these second-generation men and women, the evoking of shared histories and the construction of authentic bilingual identities are variously manipulated in their doing of friendship. For the Vietnamese women, the hyphen is strongly operationalized with an emphasis on LM and lifestyle alignments in all contexts while for the Greek women, friendship constructs the "other" aspect of the hyphen with a reliance on English. Greek men construct an imperative for LM alignment in friendship that becomes highlighted in performances of attitude and authenticity. Thus we have shown how augmenting the dynamics of co-presence with issues of hyphenated belonging provides insights into LM alignments and constraints.

\section{Concluding remarks}

In this article we explored LM practices and alignments in friendship contexts among second-generation migrants of Vietnamese, German, and Greek background. By drawing upon survey and interview data, we exposed friendship as a particularly complex yet powerful site for LM for many second-generation members. The survey data on reported use reveal that LOTE still features strongly in many peer-group-based friendships. Whilst this finding does not undermine observations about the (very) high use of English by the second generation outside the home and family, it does point to the need for further research into the intersection between friendship, LM, and second generation across various ethnolinguistic communities in Australia. The interview data in conjunction with the survey results allowed us to explore the complexities of friendship as a site for LM among the second generation.

We identified co-presence as an essential yet not sufficient ingredient for LM practices and alignments. For German women co-presence is often sought out in response to the decreasing opportunities for LM in their home and family contexts. On the other hand, the German men's non-alignment to LM in friendship occurs despite co-presence of German speaking peers. Rather, it is their sensitivity to the discourses 
of masculinities and power that results in a muting of LM (see Winter and Pauwels 2005). LM alignments intersect with gendered constructions of friendship and same-age peer interaction. We noted that while there is no muting of LM (yet?) among Vietnamese second-generation men, their responses do echo the linguistic competency voices of the German men.

LM alignments in friendships are influenced by and intersect with hyphenated belongings and migration histories. Hyphenated belongings are variously constructed in friendship contexts. Co-presence and the shared histories from the migrating first generation are counter-balanced by the participation in the discourses and language of settlement - English. Migration vintage and generation were exposed in the friendship and LM alignments for the Vietnamese (recent and ongoing) and German (older, postwar) second-generation participants. Responses to the recency or distance of migration were complex and resulted in varying LM alignments. Vietnamese women's hyphenated belongings reflect difference across the hyphen with strong LM alignments, while for the German women, shared (fading) histories were sought out through friendships with hyphenated others to reconstruct LM alignments. For these women, friendship provides a relational genre (O'Connor 1992) that sustains their LM alignments and replaces many traditional family relations.

Co-presence was a strong component in the friendship networks for second-generation Greek women, and yet LM alignment could not be guaranteed, in contrast to their male counterparts. For these young women, English dominates their feminine, frequently dyadic, friendships, constructing a separation from their family and home domain. Their hyphenated belongings mirror that of Vietnamese women to the extent that difference is the resulting outcome. In contrast, however, the separation or difference between the two hyphen-separating belongings is a corresponding split between family and home (Greek-) and friendship (-Australian).

Friendship is a multifaceted site, imbued with meanings of independence, subject to differing opportunities meshed with hyphenated belongings and gendered ethnolinguistic identities. LM alignments in friendship are both constrained and empowered by masculinities and femininities situated in a matrix of localized and shared histories and practices. The LM alignments and identity constructions that emerge in friendship point to the significance of friendship (Giddens 1992), and ethnographic work will explore the extent to which it is of increasing importance to the second-generation/first-generation locals settled in Australia. 


\section{Notes}

1. The authors would like to acknowledge the members of the Vietnamese, Greek, and German immigrant communities and the community research assistants who helped us with the research - Ms. Connie Giannicos, Ms. Tina Isaakidis, Mr. Hai Nguyen, Ms. Mai Nhu Pham, and Dr. Andrea Truckenbrodt.

2. Pseudonyms are used in order to ensure anonymity for and confidentiality of participants.

3. An honorific.

\section{References}

Bakhtin, Mikhail (1981). The Dialogic Imagination. Caryl Emerson and Michael Holquist (trans.). Austin: University of Texas Press.

Bennett, Elizabeth J. (1990). Attitude of the second generation Dutch in Australia to language maintenance and ethnic identity. Unpublished doctoral dissertation, Department of German, Monash University.

Bettoni, Camilla (1981). Italian in North Queensland. Townsville: James Cook University.

Callan, Victor; and Gallois, Cynthia (1982). Language attitudes of Italo-Australian and Greek-Australian bilinguals. International Journal of Psychology 17, 345-358.

Clyne, Michael (1991). Community Languages. The Australian Experience. Cambridge: Cambridge University Press.

Coates, Jennifer (1996). Women Talk. Conversations between Women Friends. Oxford: Blackwell.

Gal, Susan (1978). Peasant men don't get wives: language and sex roles in a bilingual roles Language in Society 7(1), 1-17.

Giddens, Anthony (1992). The Transformation of Intimacy. Sexuality, Love and Eroticism in Modern Societies. Cambridge: Polity Press.

Goffman, Erving (1981). Forms of Talk. Oxford: Blackwell.

Goodwin, Marjorie (1990). He-said-she-said. Talk as Social Organization among Black Children. Bloomington, IN: Indiana University Press.

Harvey, Susan (1974). National language usage among Dutch and Polish immigrant children. In Social Change in Australia, D. Edgar (ed.), 131-144. Melbourne: Cheshire.

Kalantzis, Mary (1993). Hybrid cultures. Greek Australians/Australian Greeks. In Greeks in English Speaking Countries, C. P. Ioannides (ed.), 199-206. Melbourne: Hellenic Studies Forum Inc.

Kiesling, Scott F. (1996). Power and the language of men. In Language and Masculinity, S. Johnson and U. Meinhoff (eds.), 65-85. Oxford: Blackwell.

Maltz, Daniel; and Borker, Ruth (1982). A cultural approach to male-female miscommunication. In Language and Social Identity, J. Gumperz (ed.), 196-216. Cambridge: Cambridge University Press.

Milroy, Lesley (1980). Language and Social Networks. Oxford: Blackwell.

O'Connor, Pat (1992). Friendship between Women. A Critical Review. London: Harvester Wheatsheaf.

Piller, Ingrid (2001). Linguistic intermarriage: language choice and negotiation of identity. In Multilingualism Second Language Learning and Gender, A. Pavlenko, A. Blackledge, I. Piller, and M. Teutsch-Dwyer (eds.), 199-230. Berlin and New York: Mouton. 
Pujolar, Joan (1996). Masculinities in a multilingual setting. In Language and Masculinity, S. Johnson and U. Meinhoff (eds.), 86-106. Oxford: Blackwell.

Smolicz, Jerzy J.; and Harris, Roger M. (1976). Ethnic languages and immigrant youth. In Australia Talks, M. Clyne (ed.), 131-175. Canberra: Research School of Pacific Linguistics, Australian National University.

Tsokalidou, Roula (1994). Cracking the code. An insight into code-switching and gender among second generation Greek-Australians. Unpublished doctoral dissertation, Department of Linguistics, Monash University.

Winter, Joanne; and Pauwels, Anne (2000). Gender and language contact research. Journal of Multilingual and Multicultural Development 20, 508-522.

-; and Pauwels, Anne (2005). Gender in the construction and transmission of ethnolinguistic identities and language maintenance in immigrant Australia. Australian Journal of Linguistics 25(1), 153-168.

Woolard, Kathryn (1997). Between friends: gender, peer group structure and bilingualism in urban Catalonia. Language in Society 26, 533-560. 
Brought to you by | School of Oriental and African Studies (SOAS), University of London 